\title{
Práxis antecipatória e escatológica do Reino de Deus: uma percepção a partir da Escatologia de Edward Schillebeeckx
}

Anticipatory and escatological practices of the Kingdon of God:
a perception from the eschatology of Edward Schillebeeckx

Aldo Fernandes da Rocha*

\section{Resumo}

No presente artigo se encontram elementos percebidos por Edward Schillebecckx sobre a práxis do Reino de Deus como sua antecipação escatológica na vida de Jesus e na atuação de seus discípulos. O Reino de Deus é o eixo central em torno do qual se articulam a prédica e a prática de Jesus. Através de parábolas, milagres, gestos, atitudes e opções, sobretudo em sua morte e ressurreição, Jesus antecipa o Reino de Deus na história, embora seu acabamento glorioso se constitua a esperança da comunidade humana para o futuro escatológico, na parusia. A adesão de fé do discípulo ao Reino produz consequências e mudanças que se efetivam na promoção da vida em todas as esferas da experiência humana. Neste artigo, adotamos como método a pesquisa bibliográfica explicativa.

Palavras-chave: Reino de Deus. Edward Schillebeeckx. Práxis. Escatologia.

\section{Abstract}

In this article are elements perceived by Edward Schillebecckx on the praxis of the Kingdom of God as his eschatological anticipation in the life of Jesus and in the performance of his disciples. The Kingdom of God is the central axis around which the preaching and practice of Jesus is articulated. Through parables, miracles, gestures, attitudes and options, especially in his

* Artigo submetido em 20/12/18 quando o autor ainda era doutorando na PUC-Rio. 
death and resurrection, Jesus anticipates the Kingdom of God in history, although his glorious finish is the hope of the human communities for the eschatological future in the parousia. The adherence of the disciple's faith to the Kingdom produces consequences and changes that take place in the promotion of life in alls pheres of human experience. In this article, we adopt as explanatory bibliographic research method.

Keywords: God's Kingdon. Edward Schillebeeckx. Práxis. Eschatology.

\section{Introdução}

$\mathrm{O}$ interesse pela Escatologia tem crescido sempre mais na academia teológica, sobretudo a partir do Concílio Vaticano II. Conforme Cleusa Andreatta, dentre os teólogos peritos do Concílio, Edward Schillebeeckx foi um dos mais influentes, sobretudo pela sua atuação como docente nas Universidade de Lovaina e Nimega, na Holanda, que lhe creditou o convite do episcopado holandês para contribuir como perito nas sessões do Concílio. ${ }^{1}$ Desde 1947, em Lovaina, Schillebeeckx havia começado sua carreira docente ensinando Escatologia, dentre outras disciplinas.

Em 1965, ele foi um dos sócios fundadores da Concilium - Revista Internacional de Teologia, na qual ele publicou a maioria de seus artigos. Membro da Ordem dos Pregadores, e herdeiro da sólida formação teológica dominicana, Schillebeeckx deu como título à sua tese doutoral A Economia Sacramental da Salvação (1952). Segundo Borgman, ${ }^{2}$ Schillebeeckx fez da Sacramentologia o eixo fundamental de suas pesquisas, publicando posteriormente várias obras na área sacramental. Mas o autor se notabilizou particularmente após a publicação de sua trilogia cristológica: ${ }^{3}$ Jesus, a história de um vivente (1974), Cristo e os Cristãos: a história de uma nova práxis (1977), e História humana: revelação de Deus (1989). Neste artigo, vamos recolher alguns elementos da escatologia presente em algumas obras de

\footnotetext{
${ }^{1}$ ANDREATTA, C. M., Experiência salvífica cristã e pluralismo religioso em Schillebeeckx, p. 23. ${ }^{2}$ BORGMAN, E., Reflexões de Edward Schillebeeckx sobre os sacramentos e o futuro da teologia católica, p. 13.

3 A trilogia cristológica de Schillebeeckx teve sua primeira publicação no ano de 1974 considerado o ano da Cristologia - (mesmo ano em que Walter Kasper publicou Jesus, el Cristo), com a obra Jesus, a história de um vivente (cuja tradução para o português foi publicada em 2008). As outras duas obras da mesma trilogia são: Il Cristo, La storia di una nuova prassi (publicada em italiano pela Editora Queriniana [Brescia] em 1980), e História humana, revelação de Deus (publicada em português 1994).
} 
Schillebeeckx, considerando o destaque que ele dá a Jesus com o título de "profeta escatológico", e a práxis de vida de Jesus Cristo como antecipação escatológica do Reino de Deus na história, com consequências e esperançosas mudanças na vida dos discípulos que aderem pela fé à prédica, e assumem a práxis de Jesus na Comunidade eclesial. Tais mudanças tendem a alcançar e melhorar as várias esferas da convivência humana no planeta e na sociedade, enquanto se alimenta a esperança do acabamento glorioso e escatológico do Reino de Deus na vinda definitiva de Jesus, na parusia.

\section{Jesus, o profeta escatológico}

A interpretação da experiência do encontro dos discípulos com Jesus de Nazaré, gerou na comunidade cristã e na Teologia nascida a partir dela a formulação dos títulos cristológicos úteis para destacar o que havia de mais relevante na pessoa de Jesus e na revelação divina que nele se manifestava. Dentre tantos títulos dados a Jesus, encontramos nos Evangelhos alguns como: "Filho de Deus", "Filho de Davi", "Filho do Homem", "o Nazareno", "o Logos", "o Crucificado", "o Ressuscitado", "o Cristo" e "o Messias". Todos os títulos cristológicos nasceram da reflexão sistemática sobre o significado da experiência do encontro com Jesus, e de uma identificação interpretativa, já inerente à experiência do próprio encontro com aquele que foi sendo assimilado na fé dos discípulos como o mediador histórico da salvação divina. Os títulos cristológicos, por si, são confissões da fé daqueles que conviveram com Jesus e dos demais que receberam por tradição (transmissão) os relatos da experiência do encontro com Jesus, com sua mensagem, suas ações benfazejas, sua morte e ressurreição.

$\mathrm{Na}$ obra cristológica de Schillebeeckx, o título mais recorrente dado a Jesus é exatamente aquele que lhe confere a missão de "profeta escatológico", oriundo de uma primeira interpretação pré-neotestamentária do "fenômeno Jesus". ${ }^{4}$ Conforme Franco Giuliano Brambilla, trata-se de um conceito intertestamentário que, porém, nos remete à tradição deuteronomista mais antiga (Dt 18,15-19; 30,15-20;32,2). Estes textos se referem à profecia de um "Anjo enviado diante de ti" (Ex 23,20), e o envio de um "profeta como eu (= Moisés) no meio de ti" (Dt 18,15). ${ }^{5}$

A tradição de um profeta do final dos tempos, mais que a espera de Elias (Ml 3,1.23-24), pertencia à tradição mosaica. No judaísmo, a figura de Elias começa a funcionar como a do precursor do profeta escatológico, do Ungido.

\footnotetext{
${ }^{4}$ SCHILLEBEECKX, E., Jesus, a história de um vivente, p. 170

${ }^{5}$ BRAMBILLA, F. G., La Cristologia di Schillebeeckx, p. 123.
} 
Segundo Brambilla, na tradição deuteronomista, Moisés é um profeta: um mensageiro sofredor. Ele é um intermediário entre Deus e o povo (Dt 5,5), que assume o sofrimento por causa de sua missão de defensor que intercede pelo povo (Dt 9,15-19; 9,25-29). Os grandes profetas gostam de se apresentar com os traços de Moisés (tais como: Jeremias - Jr 15,1; Elias e Eliseu - 1Rs 19,1921; 2Rs 2,1-15, confrontar com Dt 34,9 e Nm 27,15-23). YHWH falava com Moisés "face a face", como um homem fala com outro (Ex 33,11; Nm 12,6-8). Por fim, segundo a tradição deuteronomista, Moisés é Ebed YHWH, o Servo de Deus (Ex 24,31; Nm 12,7-8; Dt 34,5; Is 1,27; 59,10-16; 63,11). Moisés é o servo sofredor de Deus, carrega os pecados do povo (confrontar Nm 17,14 com Is 53,4). ${ }^{6}$

Além disso, Moisés é o "profeta e o Servo sofredor de Deus", conforme imagem que aparece nos cânticos do Servo sofredor em Is 42,1-4; 49,1-6; 50,411a; 52,13-53,12. Porém, o Dêutero-Isaías apresentou a figura do "servo sofredor" com os traços da figura emergente do "profeta escatológico" maior que Moisés, que - na obra de Schillebeeckx - apontam para Jesus: mediador da lei e da justiça (Is 42,6; 49,8 - Mt 5,21-48); "luz do mundo" (Is 49,4-9; 42,1-6 - Jo 8,12); intermediário da aliança (Is 42,6; 49,8 - Lc 22,20). Ele é o guia do novo Êxodo, no qual o profeta escatológico maior que Moisés vai fazer jorrar de novo a água do rochedo e dará ao povo a água da vida (Is 41,18; 43,20; $48,21 ; 49,10$ - Jo 4$)$.

Segundo Schillebeeckx, fundamentalmente importante é a pesquisa sobre a "identificação da pessoa de Jesus com o profeta messiânico do evangelho escatológico sobre a chegada do Reino de Deus, como elo entre o Jesus histórico e o Cristo querigmático", ${ }^{7}$ porque as tradições que geraram o Novo Testamento revelam profunda unidade, ainda que em correntes paralelas. Para o teólogo dominicano, "o Novo Testamento é globalmente, com fé, reflexo da atuação histórica de Jesus de Nazaré". ${ }^{8}$

Portanto, a expressão "profeta escatológico" designa um profeta que tem a pretensão de levar à humanidade uma mensagem de validade escatológica para a história presente e futura do mundo. Jesus estava persuadido da importância escatológica de sua pessoa: "Bem-aventurado aquele que não ficar escandalizado por causa de mim!" (Lc 7,23; Mc 11,6). Jesus compreendia a si mesmo na relação adotada pela humanidade com referência a ele, e desta relação dependia o destino último das pessoas, portanto, seu futuro escatológico: "Todo aquele que se declarar por mim diante dos homens, o Filho

\footnotetext{
${ }^{6}$ BRAMBILLA, F. G., La Cristologia di Schillebeeckx, p. 124-125.

${ }^{7}$ SCHILLEBEECKX, E., Jesus, a história de um vivente, p. 516.

${ }^{8}$ SCHILLEBEECKX, E., Jesus, a história de um vivente, p. 516.
} 
do Homem também se declarará por ele diante dos anjos de Deus" (Lc 12,8-9; Mc 10,32-33; confrontar com Lc 7,18-22; Mc 11,2-6; ver Lc 11,20; Mc 12,28, que é desenvolvido em seguida nos sinóticos: Mt 12,32; Lc 12,10; Mc 3,28-29).

\section{Reino de Deus antecipado no anúncio e na práxis de Jesus Cristo}

Tal como o título "profeta escatológico", atribuído por Schillebeeckx a Jesus de Nazaré, o conceito de Reino de Deus ocupa lugar central no curso do pensamento do autor, seja como principal interesse da pregação de Jesus, seja como práxis adotada pelo mesmo Jesus, bem como realidade produzida pela continuidade de idêntica prédica e prática na vida dos seus discípulos, que são os destinatários do Reino.

A práxis do Reino aparece como temática transversal em toda a obra de Schillebeeckx, cuja finalidade é fazer brilhar em Jesus sua missão de enviado do Pai para tornar o Reino compreendido e visível na história através do anúncio da salvação para a humanidade, concretizada na devolução da vida negada aos pobres, já nas circunstâncias materiais e urgentes, e implantar neles a esperança do amor divino que os chama à vida plena no futuro escatológico. O Reino é a vida de Jesus e, para torná-lo visível na vida das pessoas, Jesus está disposto a gastar a própria vida. ${ }^{9}$

O Reino é expressão da natureza de Deus, amor soberano e incondicional, na medida em que este se cumpre nas vidas de homens e mulheres que fazem a vontade de Deus e se manifesta nos mesmos. O Reino significa também "uma nova relação dos seres humanos com Deus, que tem como aspecto tangível e visível um novo tipo de relação libertadora entre homens e mulheres dentro de uma sociedade reconciliada e pacífica". ${ }^{10}$ A imaginação humana não consegue especificar os termos do que o Reino significa, mas pode se aproximar de sua realização sensível e antecipada na história através das experiências humanas de bondade, sentido e amor, bem como em qualquer situação em que a humanidade se encontre ameaçada, escravizada e obscurecida, até ao ponto de suscitar as mesmas atitudes, por vezes rebeldes, de Jesus, ao ponto de que, quem adere pela fé à pessoa e à mensagem de Jesus, acabe por dar à sua vida a mesma forma que teve a vida dele, e abraçar a causa do Reino, que ele abraçou. Nisso, pode-se ter uma visão eficaz do que venha a ser o Reino de Deus.

\footnotetext{
${ }^{9}$ SCHILLEBEECKX, E., Jesus, a história de um vivente, p. 150-164.

${ }^{10}$ SCHILLEBEECKX, E., Jesús en nuestra cultura, p. 31.
} 
Do anúncio do Reino feito por Jesus (Mc 1,15; Lc 11,20; Mt 3,2; 4,17; 10,7), à confissão de fé pós-pascal da Comunidade cristã em Jesus como o Cristo, podemos conhecer o significado permanente e decisivo da proximidade do Reino de Deus, e, por ele, da salvação total e completa trazida por Jesus à humanidade. Agir como Jesus agiu significa assumir a mesma práxis do Reino de Deus: salvar a humanidade.

Em Jesus, o anúncio do Reino, a proximidade deste percebida pelos pobres, pecadores, e todos os que a Jesus aderem pela fé, bem como os sinais (milagres) operados por Jesus, constituem realidades inseparáveis, um todo que convencionamos chamar anúncio e práxis do Reino de Deus. Inaugurado por Jesus, este itinerário existencial, uma existência segundo o Reino de Deus, prolonga-se ao longo da história, por mandato do próprio Jesus, na mensagem e nas atividades dos seus discípulos. "O fundamento do estilo de vida dos discípulos de Jesus se baseia no estilo de vida que o mesmo Jesus viveu". ${ }^{11}$ E a mesma história da salvação, que é história do Reino, e o Reino sendo revelado ao longo da história, caminham rumo à sua plenitude em Deus, após a volta definitiva do Filho (parusia), como Juiz escatológico para o juízo de vivos e mortos, para recompensar a cada um conforme sua adesão ao Reino e respectiva conduta, segundo o Reino, ou oposta a ele (Mt 25,31-46). Na segunda obra de sua trilogia, Schillebeeckx comenta a busca da justiça do Reino na práxis dos discípulos de Jesus. ${ }^{12}$

É surpreendente, para Schillebeeckx, a íntima conexão existente entre Jesus, sua mensagem (anúncio) e sua ação (práxis do Reino). "Com sua pessoa, mensagem e estilo de vida, Jesus aparece como garante do Deus libertador que ama aos homens e mulheres", ${ }^{13}$ resultando daí uma vida positiva para a humanidade. A proclamação e estilo de vida de Jesus se interpretam mutuamente, e não há quem escute o anúncio do Reino feito por Jesus, e se depare com seus gestos salvíficos, ou ateste seus milagres, que consiga ficar neutral: o Reino que em Jesus se aproxima, de algum modo, clama pela conversão daqueles que o encontram, e, se lhe permitem agir em si, mudam de vida para daí em diante se tornarem discípulos do Reino em mensagem e em atitudes a ele correspondentes.

Supõe-se que o mesmo Jesus foi confirmado da parte de Deus. A tradição cristã confirmou com seu Credo que a relação entre Jesus e Deus foi de Filho para Pai: ele é o Filho de Deus. A experiência que Jesus teve com Deus foi a

\footnotetext{
${ }^{11}$ SCHILLEBEECKX, E., Jesús en nuestra cultura, p. 34.

${ }^{12}$ SCHILLEBEECKX, E., Cristo y los cristianos, p. 528-531.

${ }^{13}$ SCHILLEBEECKX, E., Jesús en nuestra cultura, p. 34.
} 
mesma experiência judaica do $A b b a$, e tal experiência se constituiu como a fonte de sua mensagem, do anúncio do Reino do Pai, de seu estilo de vida e de sua proximidade aos pecadores, doentes e de todos os que tinham sido excluídos da salvação.

\section{Morte e Ressurreição de Jesus: antecipação escatológica do Reino de Deus}

A mensagem e práxis do Reino se constituíram em ameaça mortal e fatal para Jesus. Como João Batista e os demais profetas, Jesus, o profeta escatológico dos últimos tempos, maior que Moisés, a fetou a Herodes Antipas e ao Sinédrio, ou seja, ao poder temporal e religioso de seu tempo. O humilde e potente Reino de Deus entrou em rota de colisão com os poderes vigentes na inteira Palestina. De um lado, o humilde e potente poder de restituir a vida aos semimortos que jaziam sob o poder que a práxis dos fariseus faziam da Lei; do outro, o Sinédrio e os fariseus que instigavam as multidões e estas a Herodes e Pilatos para que condenassem Jesus à morte de cruz.

Segundo Schillebeeckx, a morte de Jesus está intimamente ligada à sua mensagem e práxis do Reino, e Jesus está consciente do significado de sua morte: é pela causa do Reino que ele vai morrer. ${ }^{14}$ Apesar da consciente iminência de sua morte (Jo 13,1), Jesus permanece fiel à sua mensagem, toma decididamente o caminho de Jerusalém (Lc 9,51), e celebra sua despedida pascal com os discípulos numa Ceia (Mc 14,12-17), advertindo-os a respeito do significado escatológico da mesma Ceia: “... já não a comerei até que ela se cumpra no Reino de Deus" (Lc 22,16).

Para Schillebeeckx, a morte de Jesus foi a consumação de sua mensagem e estilo de vida: "ele sofreu por e para os outros, como validação incondicional de uma práxis que implicava o fazer o bem e opor-se ao mal e ao sofrimento. Temos, pois, de tomar a vida e a morte de Jesus como uma entidade única". ${ }^{15}$ O sentido de sua morte não pode ser isolado do sentido de sua vida. Além disso, tendo se recusado desde o início do seu ministério público a ser identificado com um Messias triunfal, o significado da morte dele é um atestado de coerência. A ele só se pode aplicar o título de Messias se considerado ao Servo sofredor de YHWH (Is 42; 49; 52-53). Portanto, a morte de cruz redimensiona o título de Messias, de modo que a Comunidade cristã passa a identificar Jesus crucificado como o Messias. Tendo se aproximado e se identificado radicalmente com os pecadores e excluídos do Reino, Jesus assumiu todos em

${ }^{14}$ SCHILLEBEECKX, E., Jesús en nuestra cultura, p. 35-36.
${ }^{15}$ SCHILLEBEECKX, E., Jesús en nuestra cultura, p. 36. 
si na sua morte humilhante e excludente, e os introduziu no Reino de Deus com sua ressurreição, ao vencer a própria morte.

A ressurreição de Jesus foi ação escatológica de Deus, que conectou a vida histórica de Jesus - de modo superior à ruptura de sua morte - com o Cristo da fé da Igreja. Com a ressurreição, o Pai autentica a pessoa, a mensagem e o estilo de viver de Jesus; aprova o que o Filho fez e reprova o que os seres humanos fizeram com o Filho. Igual ao significado da morte, a ressurreição de Jesus não se separa de sua vida e de sua morte. A ressurreição de Jesus é também um avanço ou manifestação de algo já presente na vida e morte de Jesus: sua comunhão de vida ou graça com o Deus vivente, comunhão que não podia ser rompida com a morte, e esta comunhão, já na terra, é o início do que logo se passou a chamar de "vida eterna". Segundo Schillebeeckx, a ressurreição de Jesus reveste um significado eminentemente escatológico: não se trata apenas de uma continuidade de comunhão de vida de Cristo com Deus, mas da instauração em gérmen do Reino de Deus que se revela na exaltação e glorificação de Jesus como Deus, tornado Senhor (Kvpıos) pelo próprio Pai, e atestado em seu senhorio dentro da Comunidade que professa sua fé, dizendo: "Creio em Jesus, o Senhor". ${ }^{16}$

Num aquilino olhar teológico, Schillebeeckx percebe que tudo o que acima foi exposto sequer merece ser considerada uma boa teologia se excluímos a viva presença "pneumática" de Jesus em sua Igreja. Para Schillebeeckx, a ressurreição de Jesus, seu envio do Espírito, o surgir da comunidade de Deus, como a Igreja de Cristo que vive do Espírito e o testemunho do Novo Testamento acerca de tudo isso, assim como também a fé na ressurreição, se definem reciprocamente, ainda quando uma não possa ser identificada com a outra. O autor afirma que a Igreja que surgiu na base da fé na ressurreição de Jesus é o significado mais profundo das aparições de Jesus. Na Igreja reunida, Jesus crucificado se torna presente como ressuscitado. Onde a Igreja de Jesus Cristo está viva e Jesus é seguido em oração e libertação, a fé na ressurreição não experimenta crise alguma.

Porém, fiel ao seu critério hermenêutico fundamental, Schillebeeckx prefere não reconhecer a Deus e não crer na vida eterna, do que crer em um Deus que despreza, oprime e humilha a humanidade com o seu olhar fixado no além, pois no evangelho cristão, tanto "Deus" como "Jesus" adquirem um poder libertador, crítico e produtivo, e este critério de "humanização" proclamado por Jesus, acima de todas as expectativas humanas do humanum, que é desejado e constantemente ameaçado, e o pathos pela humanidade do ser

${ }^{16}$ SCHILLEBEECKX, E., Jesús en nuestra cultura, p. 41. 
humano, por nossa integridade e sanação, como algo próximo ao coração de Deus, não significam uma redução do evangelho, pois o evangelho significa boa nova não somente aos olhos de Jesus, mas também aos olhos do Deus de Jesus, o criador do céu e da terra, o Deus de todos os homens e mulheres. "A mensagem de Jesus abarca o Reino de Deus em toda a sua profundidade, altura e longitude; não simplesmente o perdão dos pecados e a vida eterna, aspectos também incluídos". ${ }^{17}$ Trata-se de algo muito superior a tudo isso, pois Jesus proclamou a proximidade absoluta, gratuita e efetiva do Deus que cria e traz a salvação.

Por fim, Schillebeeckx indica que, partindo da mensagem e estilo de vida de Jesus, ou seja, do anúncio e da práxis do Reino de Deus, palpita na humanidade um futuro escatológico esperado, um vir-a-ser, como algo buscado e continuamente encontrado em forma fragmentária e de novo ameaçada, que são a perfeição escatológica e a liberdade. Essas duas aspirações, segundo o Autor, só podem ser entendidas e expressas em linguagem simbólica e metafórica. Três grandes metáforas, expressas com distintas variantes na Bíblia cristã e judaica, nos sugerem a direção do que a humanidade pode chegar a ser:

a) A salvação definitiva ou libertação radical da humanidade para converter-se em uma sociedade de irmãos e irmãs, em uma comunidade viva em que já não existam as relações "senhor-servo", da qual a dor e as lágrimas desaparecem após terem sido ouvidas, se chama "Reino de Deus";

b) A salvação completa e a felicidade do indivíduo (chamado sarx, corpo ou carne na Bíblia), dentro de uma comunidade perfeita, a tradição cristã chama de "ressurreição da carne", isto é, a pessoa humana incluindo sua corporeidade humana, corporeidade como uma orquestração visível, a melodia distintiva de uma pessoa que os demais desfrutam;

c) Finalmente, consumação do "ambiente ecológico" puro que os seres humanos necessitam para viver nele, vem sugerida pela grande metáfora do "novo céu e a nova terra". ${ }^{18}$

Estas três visões metafóricas do futuro, previstas por Deus para a humanidade, orientam já a ação dos cristãos no mundo, não de um modo indeterminado ou indireto, mas de uma direção muito definida, indicada pela dinâmica destes três símbolos: inquietude por uma sociedade melhor para toda a humanidade, especialmente para os marginalizados, excluídos e isolados; inquietude pastoral pela comunicação, concebida como um criticismo social e cultural constantes, lá onde a injustiça é evidente; inquietude pelo corpo humano, a saúde psicológica e sociológica; inquietude também pelo entorno

${ }^{17}$ SCHILLEBEECKX, E., Jesús en nuestra cultura, p. 42.

${ }^{18}$ SCHILLEBEECKX, E., Jesús en nuestra cultura, p. 43-44. 
natural humano, pelo conjunto da fé cristã, esperança e amor, pela oração litúrgica e os sacramentos para que sejam significativos; e finalmente, inquietude por uma pastoral individual, que alcance especialmente até os solitários e carentes de esperança. Assim, a espiritualidade cristã adquire seu poder e sua alegria desta esperança escatológica com a qual os cristãos realizam tudo isso.

\section{Conclusão}

Emergente no recente cenário teológico internacional, Schillebeeckx tem merecido destaque na apreciação de estudantes que se devotam à pesquisa de temáticas escatológicas. Sua cristologia contém uma semântica escatológica que chama a atenção do leitor pela originalidade de termos como "profeta escatológico" e "práxis do Reino", bem como pela tematização do anúncio e práxis como antecipação escatológica do Reino de Deus na vida de Jesus Cristo e dos discípulos.

Uma leitura atenta de suas obras permite colher a longevidente percepção escatológica que Schillebeeckx tem da antecipação do Reino e sua abrangência na história. Seu rigor científico, que elabora os dados da recente pesquisa exegética, fiel ao estudo da história das formas dos textos bíblicos, particularmente dos Evangelhos, oferece ao estudante grande riqueza de informações e reflexões sobre os dados bíblicos e teológicos em vista da conversão a Jesus Cristo e consequente empenho pastoral na realidade em que o discípulo de hoje é chamado a viver nos tempos e lugares teológicos em que atua.

Como tratado teológico, a Escatologia ainda tem muito a se desenvolver e se enriquecer, desde que sejam fielmente preservadas as fontes dogmáticas da verdade revelada, sem que lhe falte a necessária ousadia para anunciar o Evangelho do Reino mesmo diante dos desafios dos anti-Reinos que surgem a cada tempo na vida da Igreja. E, neste contexto, em que a pesquisa teológica se encontra em franco desenvolvimento, percebemos que a Escatologia de Schillebeeckx tem muito a contribuir e iluminar.

\section{Referências bibliográficas}

ANDREATTA, C. M. Experiência salvífica cristã e pluralismo religioso em Schillebeeckx. Rio de Janeiro, 2003. 418p. Tese. Faculdade de Teologia, Pontifícia Universidade Católica do Rio de Janeiro.

BORGMAN, E. Reflexões de Edward Schillebeeckx sobre os sacramentos e o futuro da teologia católica. Concilium, n.344, p. 13-28, jan./mar. 2012. 
BRAMBILLA, F. G. La Cristologia di Schillebeeckx. La singolarità di Gesù come problema di ermeneutica teologica. Publicazioni del Pontificio Seminario Lombardo in Roma. Brescia: Morcelliana, 1989.

SCHILLEBEECKX, E. Cristo y los cristianos. Gracia y liberación. Madrid: Ediciones Cristiandad, 1982.

SCHILLEBEECKX, E. Jesus, a história de um vivente. São Paulo: Paulus, 2008. SCHILLEBEECKX, E. Jesús en nuestra cultura. Mística, ética y política. 2.ed. Salamanca: Ediciones Sígueme, 2001.

\section{Aldo Fernandes da Rocha}

Doutor em Teologia pela Pontifícia Universidade Católica do Rio de Janeiro

Rio de Janeiro / RJ - Brasil

E-mail: af35@bol.com.br

Recebido em: 20/12/18

Aprovado em: 27/11/19 